\title{
Literature :
}

1) Y. Onoue, Y. Mizutani, R. Yamane, W. Teshima, S. Akiyama, Denki-Kagaku 29, 468 (1961), This Journal 29, E 226 (1961).

2) Y. Onoue, Y. Mizutani, R. Yamane, Denki-Kagaku 27, 482 (1959).

\section{Studies on Ion Exchange Membranes. VIII. On the Anion Exchange Membranes Using Dimethyl (2-oxybenzyl) Amine*}

\author{
Yasuharu OnOue, Yukio Mizutani, Yūsuke Izumi \\ Tokuyama Soda Co., Ltd., Tokuyama, Yamaguchi
}

\section{Introduction}

There are many reports ${ }^{1)}$ about the anion exchange membranes and resins prepared by polycondensation. In these exchangers amine groups are usually used as the ion exchange sites in the form of polymer chain unit but not in the form of side chain. For example, the preparation of the anion exchange membranes using tetraethylene pentamine was already reported ${ }^{2,3)}$.

Usually, amine groups are sensitive to oxidation. So, if amine groups were used in the form of polymer chain unit, not only the losses of ion exchange sites, but also the scissions of the polymer chains could be induced by the oxidative attack. On the other hand, if amine groups were used in the form of side chain, the losses of ion exchange sites could be occured, but the scissions of polymer chains could be hardly induced under the same conditions. It would be anticipated that the latter should be more stable than the former for the oxidative attack.

From the viewpoints described above, the anion exchange membranes using dimethyl (2-oxybenzyl) amine were prepared and their electrochemical properties and stabilities were measured.

\section{Experimental}

(1) Dimethyl (2-oxybenzyl) Amine [DMBA] Dimethyl (2-oxybenzyl) amine was prepared by Mannich's reaction.

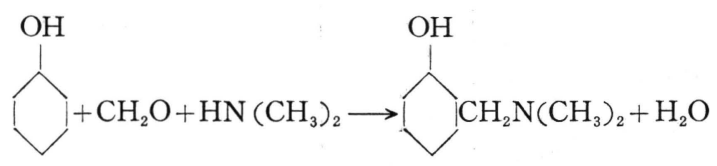

(2) Preparation of Membranes The materials (DMBA, phenol, 37\% formaline and $\mathrm{H}_{2} \mathrm{SO}_{4}$ $\mathrm{CH}_{3} \mathrm{COOH}$ ) with the appropriate molar ratio were mixed under cooling and stirring, and the mixtures of the materials were stirred for 1 hour at $50-60^{\circ} \mathrm{C}$. Thus, the viscous resinous solutions were obtained. These solutions were laminated with glass clothes and cured at $60-70^{\circ} \mathrm{C}$ for 8 hours.

The ion exchange sites of the prepared membranes were tertiary amine groups (TA membranes). TA membranes were quaternized with $\mathrm{CH}_{3} \mathrm{I}-\mathrm{CH}_{3} \mathrm{OH}$ (1:1 in volume) at room temperature (QA membranes).

(3) Measurement Water content, exchange capacity, specific conductivity and membrane potential were measured by the preceding methods ${ }^{2}$. Specific conductivities were measured in $0.5 \mathrm{~N}$ $\mathrm{NaCl}$ at $25^{\circ} \mathrm{C}$. Transport numbers were calculated from the membrane potential by Nernst's equation, which was measured with $0.5 \mathrm{~N} \mathrm{NaCl}$ and $2.5 \mathrm{~N} \mathrm{NaCl}$ at $25^{\circ} \mathrm{C}$.

* The original written in Japanese can be seen in Denki-Kagaku 29, 653 (1961). 
(4) Degradation Test TA membranes $\left(5 \times 5 \mathrm{~cm}^{2}\right)$ were treated with the bleaching solutions (bleaching powder $5 \mathrm{~g} /$ water $1000 \mathrm{cc}$ ) at room temperature. The bleaching solutions were renewed every 24 hours. Dry resin weights before treatment were compared with dry resin weights after treatment. For comparison, teraethylene pentamine membranes (TP membranes) ${ }^{2), 3)}$ were treated similarly.

(5) Electrophoretic Concentration of Sea Water Sea water was used after simple filteration. The polycondensed cation exchange membranes were used together. Experimental conditions were as follows :

$$
\begin{array}{ll}
\text { current density : } & 0.8 \mathrm{~A} / \mathrm{dm}^{2} \\
\text { temperature of sea water } & : 25^{\circ} \mathrm{C} .
\end{array}
$$

\section{Results and Discussion}

(1) Properties The electrochemical properties of TA membranes are shown in Table 1.

The properties of quarternized TA membranes, QA membranes, are shown in Table 2.

QA membranes are superior to TA membranes in specific conductivities, but not in transport numbers.

Table 1 Properties of TA membranes

\begin{tabular}{l|c|c|c|c}
\hline \hline \multicolumn{1}{c|}{ DMBA/Phenol } & 1.0 & 1.5 & 2.0 & 2.5 \\
\hline Water content & 0.22 & 0.27 & 0.43 & 0.49 \\
Exchange capacity & 2.14 & 2.41 & 2.55 & 2.60 \\
Specific conductivity & $1.2 \times 10^{-3}$ & $3.5 \times 10^{-3}$ & $4.5 \times 10^{-3}$ & $9.1 \times 10^{-3}$ \\
Transport number & 94 & 94 & 93 & 88 \\
\hline DMBA/Phenol & $:$ molar ratio, & & \\
Water content & $: g-\mathrm{H}_{2} \mathrm{O} / g$-dry Cl form resin, & \\
Exchange capacity & $: \mathrm{Milli}^{-1}$ equivalent/g-dry Cl form resin & & \\
Specific conductivity & $: \Omega^{-1} \mathrm{~cm}^{-1}$ &
\end{tabular}

Table 2 Properties of QA Membranes with Different Treating Times

\begin{tabular}{l|c|c|c|c|c}
\hline \hline \multicolumn{2}{r|}{ DMBA/Phenol } & & & \\
Treating & & 1.0 & 1.5 & 2.0 & 2.5 \\
& 1 & & & & \\
\hline & 2 & $2.3 \times 10^{-3}$ & $3.9 \times 10^{-3}$ & - & $11.1 \times 10^{-3}$ \\
Specific conductivity & 3 & $1.8 \times 10^{-3}$ & $4.2 \times 10^{-3}$ & $7.0 \times 10^{-3}$ & $11.5 \times 10^{-3}$ \\
& 16 & $2.0 \times 10^{-3}$ & $4.2 \times 10^{-3}$ & $6.8 \times 10^{-3}$ & - \\
\hline \multirow{3}{*}{ Transport number } & 1 & 93 & 93 & 90 & 85 \\
& 3 & 93 & 93 & 90 & 85 \\
& 16 & 91 & 92 & 88 & 85 \\
\hline
\end{tabular}

DMBA/Phenol : Molar ratio

Treating time: hours

Specific conductivity : $\Omega^{-1} \mathrm{~cm}^{-1}$ Transport number : $\%$

Table 3 Degradation by Bleaching Solution

\begin{tabular}{c|r|r|r|r}
\hline \hline \multicolumn{2}{c|}{ Treating time } & 1 day & 3 days & 5 days \\
\hline \multirow{3}{*}{ Degree of degradation } & TA membrane & 0.94 & 0.95 & 0.95 \\
& TP membrane & 0.84 & 0.85 & 0.76 \\
\hline
\end{tabular}

TA membrane : DMBA/Phenol(molar ratio) $=1.5$

TP membrane: Specific conductivity $3.1 \times 10^{-3} \Omega^{-1} \mathrm{~cm}^{-1}$ Transport number $92 \%$

\section{(2) Degradation Degree of degradation is shown as follows:}

Degree of degradation $=$ dry resin weight after treatment/dry resin weight before treatment. 
TA membranes are more stable than TP membranes as shown in Table 3.

When TP membranes were treated, the bleaching solutions were coloured by the degradation of resins, but when TA membranes were treated, the bleaching solutions were not coloured.

These results about the stabilities of the membranes would not be applicable to degradation of the membranes in the industrial electrophoretic concentration of sea water, because the mechanism of degradation of the membranes in sea water should be very complicated.

(3) Electrophoretic Concentration of Sea Water The results are shown in Table 4.

Table 4 Ionic Compositions of Concentrated Brines

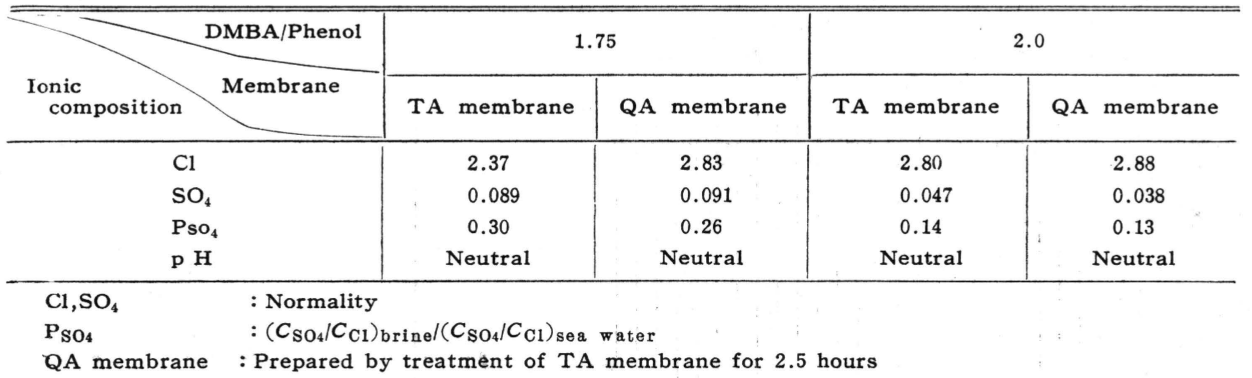

\title{
4. Conclusion
}

The anion exchange membranes having the ion exchange sites in the side chains were prepared by using dimethyl (2-oxybenzyl) amine, and some of them were quarternized with $\mathrm{CH}_{3} \mathrm{I}$. The electrochemical properties of both membranes were measured.

From the results of the degradation tests with bleaching solutions, it is concluded that dimethyl (2-oxybenzyl) amine membranes are more stable than the tetraethylene pentamine membranes.

(Received Jan. 5, 1961)

\section{Literature :}

1) F. Helfferich, "Ionenaustauscher" Band 1, Seite 42-44 (1959) Verlag Chemie GMBH, Weinheim/Bergstr.

2) Y. Onoue, Y, Mizutani, S. Akiyama, Denki-Kagaku 29, 223 (1961).

3) Y. Onoue, Y. Mizutani, R. Yamane, Ibid. 29, 294 (1961).

\section{Polarographic Studies on Nitrophenylhydrazine Isomers*}

\author{
Yoshinosuke Nagata**, Koichiro KitaO***, Isamu TACH ${ }^{* *}$ \\ ** Department of Agricultural Chemistry, Kyoto University, Kyoto \\ ** Wood Research Institute of Kyoto University, Uji, Kyoto
}

In order to study the reaction of phenylhydrazine derivatives with carbonyl compounds by the polarographic method ${ }^{1 \sim 5)}$, the polarographic behavior of $o^{-}, p^{-}$, and $m$-nitrophenylhydrazine isomers was investigated.

These compounds showed a reduction wave and an anodic wave. Characteristic values of the polarographic waves were shown in Table 1. A pre-wave is accompanied by the anodic wave in the case

* The original written in Japanese can'be seen in Denki-Kagaku 29, 768 (1961). 